\title{
Systematic review of the influence of enhanced recovery pathways in elective lung resection
}

\author{
Julio F. Fiore, Jr, PhD, ${ }^{\mathrm{a}}$ Jimmy Bejjani, MD, ${ }^{\mathrm{a}}$ Kate Conrad, MD, ${ }^{\mathrm{a}}$ Petru Niculiseanu, MD, ${ }^{\mathrm{a}}$ \\ Tara Landry, MLIS, ${ }^{b}$ Lawrence Lee, $\mathrm{PhD},{ }^{\mathrm{a}}$ Lorenzo E. Ferri, $\mathrm{PhD},{ }^{\mathrm{c}}$ and Liane S. Feldman, $\mathrm{MD}^{\mathrm{a}}$
}

\begin{abstract}
Objective: Enhanced-recovery pathways aim to accelerate postoperative recovery and facilitate early hospital discharge. The aim of this systematic review was to summarize the evidence regarding the influence of this intervention in patients undergoing lung resection.

Methods: The review was performed according to the Preferred Reporting Items for Systematic Reviews and Meta-Analyses Statement. Eight bibliographic databases (Medline, Embase, BIOSIS, CINAHL, Web of Science, Scopus, Cochrane Database of Systematic Reviews, and Cochrane Central Register of Controlled Trials) were searched for studies comparing postoperative outcomes in adult patients treated within an enhanced-recovery pathway or traditional care. Risk of bias was assessed using the Cochrane Collaboration risk of bias tool.

Results: Six studies fulfilled our selection criteria (1 randomized and 5 nonrandomized studies). All the nonrandomized studies reported shorter length of stay in the intervention group (difference, 1.2-9.1 days), but the randomized study reported no differences. There were no differences between groups in readmissions, overall complications, and mortality rates. Two nonrandomized studies reported reduction in hospital costs in the intervention group. Risk of bias favoring enhanced recovery pathways was high.
\end{abstract}

Conclusions: A small number of low-quality comparative studies have evaluated the influence of enhanced-recovery pathways in patients undergoing lung resection. Some studies suggest that this intervention may reduce length of stay and hospital costs, but they should be interpreted in light of several methodologic limitations. This review highlights the need for well-designed trials to provide conclusive evidence about the role of enhanced-recovery pathways in this patient population. (J Thorac Cardiovasc Surg 2016;151:708-15)

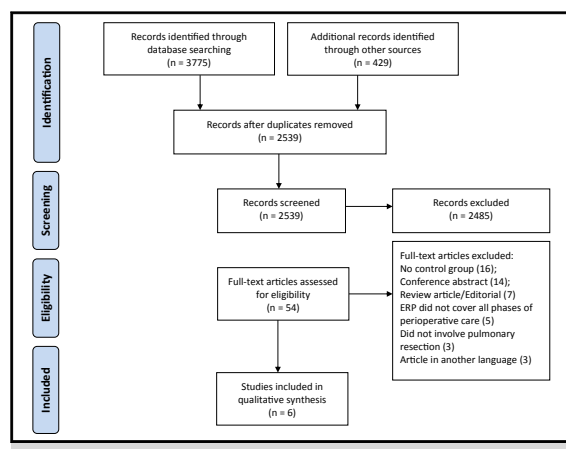

Six studies compared enhanced recovery pathways versus usual care in lung resection.

Central Message

There is no conclusive evidence about the role of ERPs in lung resection.

\section{Perspective}

A small number of low-quality comparative studies evaluated the influence of ERPs in patients undergoing lung resection. Some studies suggest that ERPs may reduce primary LOS and hospitalization costs, but risk of bias favoring the intervention was high. This review highlights the need for well-designed trials to provide conclusive evidence about the role of ERPs in lung resection

See Editorial Commentary page 715.

See Editorials page 626 and 629.

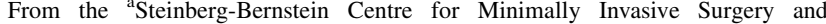
Innovation, McGill University Health Centre, Montreal, Quebec, Canada; ${ }^{\mathrm{b}}$ Montreal General Hospital Medical Library, McGill University Health Centre, Montreal, Quebec, Canada; and ${ }^{\mathrm{c}}$ Division of Thoracic Surgery, McGill University Health Centre, Montreal, Quebec, Canada.

The Steinberg-Bernstein Centre for Minimally Invasive Surgery and Innovation (McGill University Health Centre, Montreal, Quebec, Canada) is funded through an unrestricted educational grant from Covidien Canada.

Received for publication June 24, 2015; revisions received Sept 1, 2015; accepted for publication Sept 28, 2015; available ahead of print Nov 6, 2015.

Address for reprints: Liane S. Feldman, MD, Montreal General Hospital 1650 Cedar Ave, L9-404, Montreal, QC H3G 1A4 (E-mail: liane.feldman@mcgill.ca).

$0022-5223 / \$ 36.00$

Copyright $(\odot 2016$ by The American Association for Thoracic Surgery

http://dx.doi.org/10.1016/j.jtcvs.2015.09.112
Postoperative morbidity is still common after lung resection despite advances in surgical and anesthetic techniques. Complications occur at a rate of $30 \%$ to $40 \%{ }^{1,2}$ and often impair postoperative recovery, resulting in increased

Scanning this QR code will take you to supplemental data for this article. 


$$
\begin{aligned}
& \text { Abbreviations and Acronyms } \\
& \text { ERP }=\text { enhanced recovery pathway } \\
& \text { LOS }=\text { length of stay } \\
& \text { PRO }=\text { patient-reported outcome } \\
& \text { RCT }=\text { randomized controlled trial } \\
& \text { SF-36 }=\text { Short Form } 36 \\
& \text { VATS }=\text { video-assisted thoracic surgery }
\end{aligned}
$$

hospital length of stay (LOS), ${ }^{3}$ delayed return to regular activities, and poor postoperative quality of life. ${ }^{4}$ Prolonged postoperative recovery also increases heath care costs, imposing a significant economic burden. ${ }^{5}$ Therefore, improving recovery is not only desirable for patients and clinicians, but also leads to more efficient use of health care resources.

In recent years, there has been increased interest in the use of multimodal care plans to hasten postoperative recovery, reduce morbidity, and facilitate early hospital discharge. This concept of care is often referred to as fast track, enhanced recovery after surgery, or enhanced recovery pathway (ERP). ${ }^{6}$ ERPs combine multiple care elements encompassing all phases of care: preoperative (eg, counseling and nutrition), intraoperative (eg, normothermia and epidural anesthesia), and postoperative (eg, early mobilization and early feeding). ${ }^{6}$ These care elements may have modest benefits when used alone, but are believed to have a synergistic effect to attenuate surgical stress and postoperative organ dysfunction, thereby facilitating recovery. ${ }^{6}$ Most of the evidence regarding the benefits of ERPs is derived from the colorectal surgery literature, where several meta-analyses reported a significant reduction in LOS and risk of complications without increasing readmission rates. ${ }^{7}$ Evidence also supports the cost-effectiveness of ERPs in this population..$^{5}$ Although research in other surgical specialties is still limited, emerging evidence suggests similar benefits. ${ }^{7,8}$

Although the use of care pathways in lung resection was introduced more than 15 years ago, ${ }^{9}$ evidence in this field is provided largely by case-series reports. ${ }^{10-12}$ These reports show excellent results in favor of ERPs, but the absence of a control group raises questions about the degree to which improved outcomes can be attributed to the intervention as opposed to other factors such as differential selection of patients (ie, selection bias), lack of blinded outcome assessors (ie, detection bias), or changes in other aspects of patient care (ie, performance bias). The influence of ERPs on postoperative outcomes after lung resection has not been extensively studied in comparative studies involving a control group receiving traditional care. In our systematic review, we aimed to summarize and assess the quality of the evidence regarding the effects of ERPs in comparison to traditional care in adult patients undergoing lung resection.

\section{METHODS}

This systematic review was conducted according to the Preferred Reporting Items For Systematic Reviews and Meta-Analyses Statement guidelines ${ }^{13}$ and aimed to respond to the following research question: To what extent do ERPs influence postoperative outcomes after lung resection in comparison to traditional care? The review protocol was registered with the PROSPERO international prospective register of systematic reviews (CRD42013003789).

\section{Search Strategy}

Eight bibliography databases (Medline, Embase, BIOSIS, CINAHL, Web of Science, Scopus, Cochrane Database of Systematic Reviews, and Cochrane Central Register of Controlled Trials) were searched by a medical librarian (TL) from their date of establishment until June 2014. Text words and relevant indexing were used to capture the concepts of lung resection procedures (eg, lung/pulmonary resection and lobectomy) and ERPs (eg, enhanced recovery and fast track). The complete search strategies used in each database are described in Appendix E1. The reference lists of included studies and the Web sites Turning Research Into Practice (http://www.tripdatabase.com/) and International Network of Agencies for Health Technology Assessment (http://www.inahta.net/) were searched for additional relevant articles. To avoid publication bias, we searched ClinicalTrials.gov for unpublished studies. The Medline search was rerun before submission (May 21, 2015) and no additional relevant studies were found.

\section{Inclusion and Exclusion Criteria}

Studies were included if they involved adult patients undergoing elective lung resection (ie, wedge resection, lobectomy, or pneumonectomy), involved patients managed using an ERP, involved a control group receiving traditional care, reported at least 1 of the outcome measures of interest (see below), and were published in English or French. For the purpose of this review, we considered that patients were managed using an ERP if the authors documented the use of a bundle of at least 4 interventions aimed to enhance recovery, covering all phases of perioperative care (pre-, intra-, and postoperative). Because there are no standardized criteria to define what constitutes an ERP, this definition was based on previous reviews on ERPs in other surgical specialties. ${ }^{14}$ Studies were excluded if the care elements included in the ERP were not described, the ERP included fewer than 4 care elements, or the ERP did not cover all phases of perioperative care.

\section{Outcome Measures}

The main outcome of interest was primary LOS (ie, time from surgery until first discharge). Other outcomes of interest were postoperative complications, readmissions, mortality rates, and patient-reported outcomes (PROs) (ie, measures of health status collected directly from patients). Data on costs, total LOS (primary LOS plus LOS during readmission), time to functional recovery (eg, readiness for hospital discharge), and adherence to the protocol were also analyzed if available.

\section{Study Selection and Data Extraction}

Two investigators (JF, PN) independently screened the articles identified by the search. Articles that were clearly irrelevant were excluded after examination of titles and abstracts. Full-text versions of the articles potentially suitable for inclusion were retrieved and evaluated against the selection criteria. Disagreements regarding eligibility were resolved by consulting a third investigator (LSF).

Data were extracted independently by 2 investigators $(\mathrm{JB}, \mathrm{KC})$ and crosschecked. In addition to the outcome measures of interest, the following variables were obtained from the selected articles: study design, number of participants, age, gender, American Society of Anesthesiologists grade, body mass index, forced expiratory volume in 1 second, preoperative diagnosis, surgical approach (eg, video-assisted thoracic surgery [VATS] and thoracotomy), extent of resection, duration of follow-up and specific ERP elements included in the ERP. 

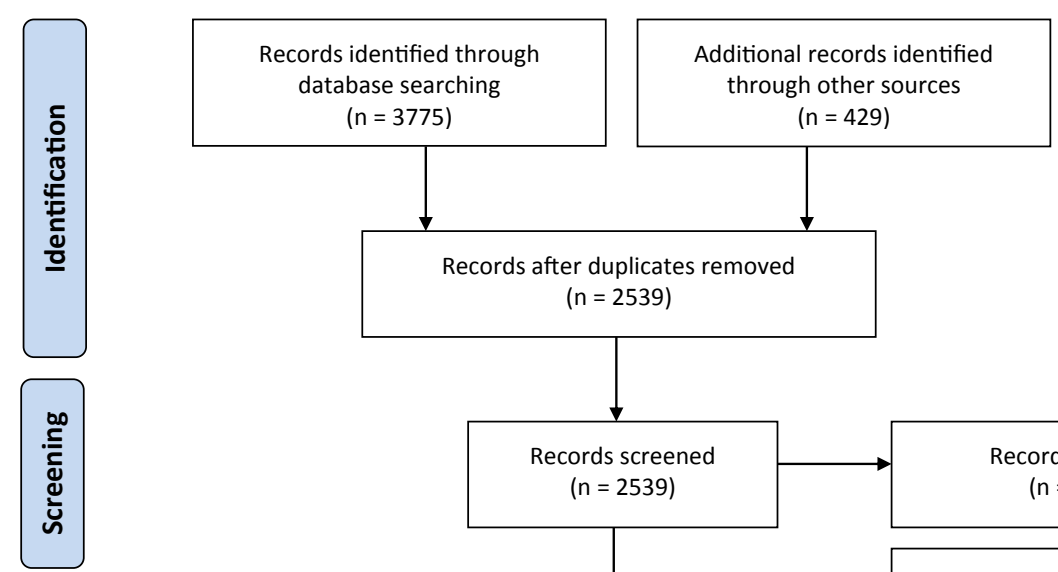

$$
(n=3775)
$$
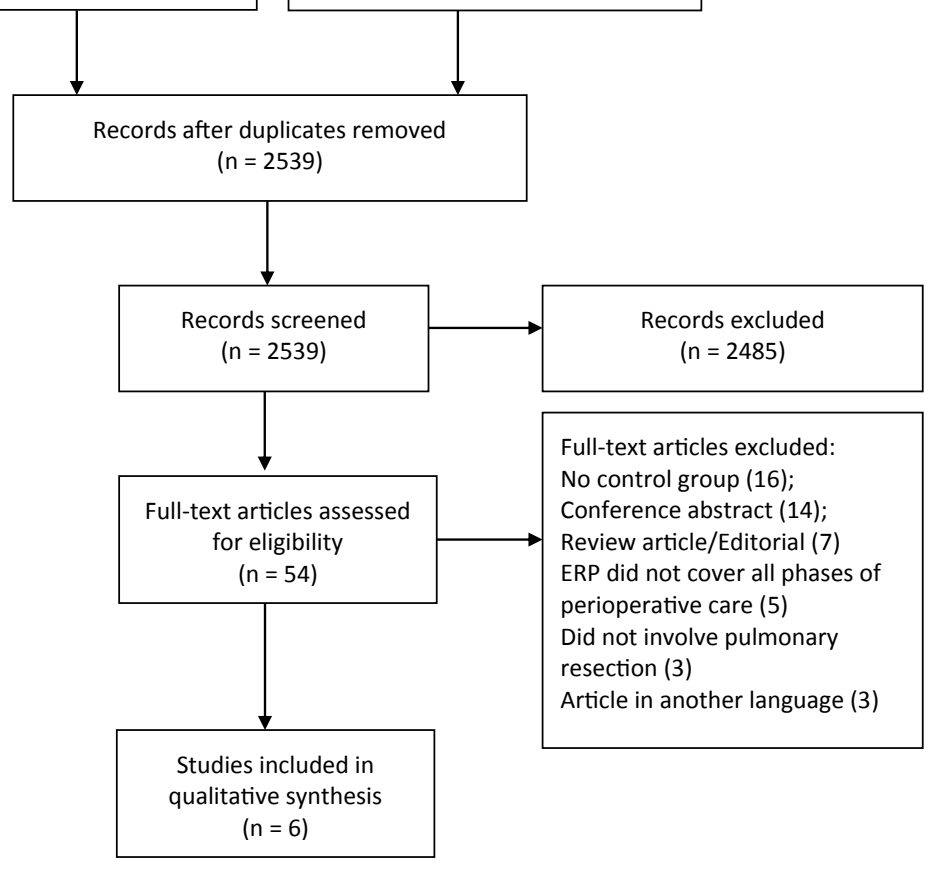

FIGURE 1. Preferred reporting items for systematic reviews and meta-analyses flow diagram. ERP, Enhanced recovery pathway.

\section{Quality Assessment}

The methodologic quality of each study was independently appraised by 2 investigators (JF, JB) using the Cochrane risk of bias tool, ${ }^{15}$ which appraises risk of bias across six domains: selection bias (random sequence generation and allocation concealment), performance bias (blinding of participants and personnel), detection bias (blinding of outcome assessment), attrition bias (incomplete outcome data), reporting bias (selective reporting), and other biases. For the domain "other biases," we considered whether the study used standardized criteria to define postoperative complications and to define readiness for hospital discharge. Although the Cochrane risk of bias tool was originally designed to evaluate risk of bias in randomized controlled trials (RCTs), its use is often extended to nonrandomized intervention studies. ${ }^{16}$ Some domains of the tool are invariably negative in the absence of randomization (eg, adequate sequence generation and allocation concealment). Due to the nature of the interventions involved in ERPs, it is often unfeasible to blind patients and staff; therefore, high risk of performance bias was assumed if a study did not mention blinding of staff or patients. In addition to the methodologic aspects covered by the Cochrane risk of bias tool, we also appraised whether a sample size calculation was performed to ensure that the study was adequately powered to detect differences between groups. Disagreements regarding the quality assessment were resolved by consulting a third investigator (LSF).

\section{Data Analysis}

Due to the lack of consistent literature or guidelines on ERPs for lung resection, we expected that there would be significant clinical heterogeneity between studies, especially in regard to the care elements

TABLE 1. Study design and quality assessment

\begin{tabular}{|c|c|c|c|c|c|c|c|c|c|c|}
\hline \multirow[b]{2}{*}{ Study } & \multirow[b]{2}{*}{ Design } & \multicolumn{2}{|c|}{ Sample size } & \multicolumn{7}{|c|}{ Quality assessment according to Cochrane Collaboration tool } \\
\hline & & ERP & Control & $\begin{array}{c}\text { Random } \\
\text { sequence } \\
\text { generation }\end{array}$ & $\begin{array}{c}\text { Allocation } \\
\text { concealment }\end{array}$ & $\begin{array}{c}\text { Blinding of } \\
\text { participants } \\
\text { and } \\
\text { personnel }\end{array}$ & $\begin{array}{l}\text { Blinding of } \\
\text { outcome } \\
\text { assessment }\end{array}$ & $\begin{array}{c}\text { Incomplete } \\
\text { outcome } \\
\text { data }\end{array}$ & $\begin{array}{l}\text { Selective } \\
\text { reporting }\end{array}$ & $\begin{array}{c}\text { Other } \\
\text { bias }\end{array}$ \\
\hline Salati, 2012 & Case-control & 232 & 232 & $(-)$ & $(-)$ & $(-)$ & (?) & (?) & (?) & $(-)$ \\
\hline Numan, 2012 & Prospective cohort & 75 & 94 & $(-)$ & $(-)$ & $(-)$ & (?) & (?) & (?) & $(-)$ \\
\hline Muehling, 2008 & $\begin{array}{l}\text { Randomized } \\
\text { controlled trial }\end{array}$ & 30 & 28 & $(?)$ & $(?)$ & $(-)$ & (?) & (?) & (?) & $(-)$ \\
\hline Maruyama, 2006 & Retrospective cohort & 113 & 105 & $(-)$ & $(-)$ & $(-)$ & (?) & (?) & (?) & $(-)$ \\
\hline Zehr, 1998 & Prospective cohort & 241 & 185 & $(-)$ & $(-)$ & $(-)$ & (?) & (?) & (?) & $(-)$ \\
\hline Wright, 1997 & Retrospective cohort & 130 & 147 & $(-)$ & $(-)$ & $(-)$ & (?) & (?) & $(?)$ & $(-)$ \\
\hline
\end{tabular}

ERP, Enhanced recovery pathway; (-), high risk of bias; (+), low risk of bias; (?), unclear risk of bias. 
included in each protocol. In addition, systematic reviews of ERPs in other surgical populations showed that heterogeneity in methodology and outcome reporting is common in this field of research. ${ }^{8}$ Pooling of data from heterogeneous studies into meta-analyses can yield misleading results ${ }^{15}$; therefore, our systematic review was reported using a narrative (descriptive) synthesis approach.

\section{RESULTS}

\section{Literature Search}

A total of 2539 unique articles were identified and 54 underwent full-text review (Figure 1). Of these, 47 were excluded (articles and reasons for exclusion listed in Appendix E2). Six articles fulfilled our selection criteria and were included in the review. ${ }^{17-22}$

\section{Characteristics of the Included Studies}

The six studies comprised $1 \mathrm{RCT},{ }^{21} 1$ case-control study, ${ }^{19} 2$ prospective cohort studies, ${ }^{17,20}$ and 2 retrospective cohort studies ${ }^{18,22}$ (Table 1). Nonrandomized studies had high risk of bias in the majority of the domains of the Cochrane Tool. The only RCT included in the review $^{21}$ had unclear risk of bias in the majority of the domains because it lacked information on randomization sequence generation, concealment of allocation, and blinding of outcome assessors. Losses to follow-up (missing data) were reported in only 1 study, but not for all outcome measures. ${ }^{20}$ All the included studies had unclear risk of selective reporting because study protocols were not available a priori. Two studies used standardized criteria to define postoperative complications. ${ }^{19,21}$ None of the studies reported the use of standardized criteria to define readiness for hospital discharge. Also, none of the studies reported a sample size calculation.

The studies involved a total of 1612 participants (821 ERP vs 791 control). Although reporting was inconsistent, patient characteristics were similar between ERP and control groups (details presented in Appendix E3). Two studies involved only patients undergoing lobectomy ${ }^{18,19}$ and 4 studies involved a variety of resection procedures (from wedge resection to pneumonectomy). ${ }^{17,20-22}$ Of three studies reporting preoperative diagnosis, 1 involved only cancer patients ${ }^{20}$ and 2 involved patients with cancer or benign diseases. $^{21,22}$ Of 3 studies reporting surgical approach, 1 included only VATS, ${ }^{22} 1$ included only thoracotomy, ${ }^{21}$ and 1 included both VATS and thoracoctomy. ${ }^{20}$ In the study by Numan and colleagues, ${ }^{20}$ the proportion of VATS was larger in the ERP group (the authors counted VATS as an ERP element).

\section{ERP elements}

A total of 15 individual ERP elements were described in the included studies (Table 2). The number of elements used within each study ranged from 4 to 10 (median, 6.5). The elements most frequently cited were preoperative education ( $n=5)$, prophylactic antibiotics $(n=4)$, epidural anesthesia/analgesia $(\mathrm{n}=4)$, standardized chest tube management $(n=5)$, and early mobilization $(n=4)$. None of the studies reported adherence to protocol elements.

\section{Hospital LOS}

All the studies evaluated primary LOS (Table 3). The nonrandomized studies reported significantly shorter LOS in patients treated within an ERP (difference, 1.2-9.1 days). ${ }^{17-20,22}$ The RCT reported no differences between groups (11 days in both groups). ${ }^{21}$ None of the studies reported total LOS.

\section{Readmission Rates}

Three nonrandomized evaluated readmission rates (Table 3). ${ }^{18-20}$ One study reported readmissions within 7 days after surgery, ${ }^{18} 1$ study reported readmissions within 30 days, ${ }^{19}$ and 1 study did not specify length of follow-up. ${ }^{20}$ Rates of readmission ranged from $1 \%$ to $10 \%$. Numan and colleagues $^{20}$ reported a higher readmission rate in the control group, and the other 2 studies reported no differences between groups. ${ }^{18,19}$

\section{Complication and Mortality Rates}

Three studies evaluated rates of postoperative complication (Table 4). ${ }^{19-21}$ One study reported complications within 30 days $^{19}$ and 2 studies did not specify length of follow-up. ${ }^{20,21}$ Complication rates ranged from $14 \%$ to $46 \%$. None of the studies showed differences in overall complications between control and ERP groups. The RCT by Muehling and colleagues ${ }^{21}$ reported a significant reduction in pulmonary complications in the ERP group. In 3 studies reporting mortality, there were no differences between groups. ${ }^{17,18,20}$

\section{Cost Analysis}

Three nonrandomized studies evaluated total hospital costs per patient. ${ }^{17,18,22}$ In the study by Maruyama and colleagues, ${ }^{22}$ costs were significantly lower in patients treated within an ERP (mean, $\$ 13,093 \pm \$ 280$ vs control $\$ 14,439 \pm \$ 430 ; P=.0002)$. Zehr and colleagues ${ }^{17}$ also reported significantly lower mean costs in the ERP group $(\$ 13,432 \pm \$ 8056$ vs control $\$ 17,103 \pm \$ 13,221$; $P<.01)$. In the study by Wright and colleagues, ${ }^{18}$ differences in hospital costs were not statistically significant (ERP $\$ 14,792$ vs control $\$ 16,063 ; P=.47$; variability not reported).

\section{PROs}

One nonrandomized study evaluated the influence of an ERP on postoperative quality of life using the Short-Form 36 (SF-36). ${ }^{20}$ At 1 month after surgery, the SF-36 Physical Summary Score was significantly higher in the ERP group 
TABLE 2. Enhanced recovery pathway elements used in each study

\begin{tabular}{|c|c|c|c|c|c|c|c|}
\hline \multirow[b]{2}{*}{ Study } & \multicolumn{3}{|c|}{ Preoperative } & \multicolumn{4}{|c|}{ Intraoperative } \\
\hline & $\begin{array}{l}\text { Patient education } \\
\text { and/or counseling }\end{array}$ & $\begin{array}{c}\text { Shorter } \\
\text { preoperative } \\
\text { fasting } \\
\end{array}$ & $\begin{array}{c}\text { Prophylactic } \\
\text { antibiotics }\end{array}$ & $\begin{array}{c}\text { Epidural } \\
\text { anesthesia/analgesia }\end{array}$ & $\begin{array}{l}\text { Use of single } \\
\text { chest tube }\end{array}$ & $\begin{array}{l}\text { Fissureless right } \\
\text { upper lobectomy }\end{array}$ & $\begin{array}{c}\text { Muscle sparing } \\
\text { surgery/VATS }\end{array}$ \\
\hline Salati, 2012 & $\boldsymbol{V}$ & & & & 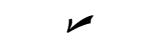 & $\nu$ & \\
\hline Numan, 2012 & $\nu$ & & レ & レ & & & レ \\
\hline Muehling, 2008 & レ* & レ & & 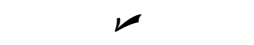 & & & \\
\hline Maruyama, 2006 & 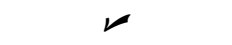 & & レ & 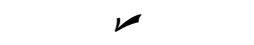 & & & \\
\hline Zehr, 1998 & & & レ & & & & \\
\hline Wright, 1997 & レ & & レ & レ & & & \\
\hline
\end{tabular}

VATS, Video-assisted thoracic surgery; $I V$, intravenous. *Interventions also used in the control group.

in comparison to the control group $(P=.03)$. The ERP group also tended to have higher Physical Summary Scores at 6 months after surgery $(P=.07)$. The authors mentioned that patients in the ERP group had lower SF-36 Bodily Pain Scores at 1,3, and 6 months but no inferential statistics were reported (eg, $P$ values).

\section{DISCUSSION}

There is a small number of comparative studies evaluating the influence of ERPs in patients undergoing lung resection. Some of these studies suggest that ERPs are safe (ie, do not result in more complications, hospital readmissions, or deaths) and have the potential to reduce primary LOS and hospitalization costs; however, risk of bias favoring the intervention was high. Elements included in the ERPs were variable and often poorly defined. This review highlights that although the use of ERPs in lung resection is potentially promising, data supporting its benefits are sparse and low in quality.

The majority of the studies reported that LOS was significantly shorter when patients undergoing lung resection were treated within an ERP, which corroborates the results observed in other surgical populations. ${ }^{8}$ Curiously, the only study reporting no differences in LOS was the RCT by Muehling and colleagues. ${ }^{21}$ Therefore, we cannot exclude that the positive results observed in nonrandomized studies may reflect selection bias associated with lack of randomization or time-dependent confounding inherent to before-and-after designs. This discrepancy of results can also be attributed to differences in statistical power or to specific protocol characteristics. For example, the ERP used in the RCT comprised some elements that were already part of traditional care in the control group and did not include a standardized protocol for chest tube management (ie, avoidance of active suction ${ }^{23}$ and low volume threshold for drain removal ${ }^{24}$ ). The latter may be a crucial element of ERPs for lung resection because chest tube duration is recognized as a major determinant of prolonged LOS in this patient population. ${ }^{3}$ Also, median LOS in the RCT was long (11 days), ${ }^{21}$ which may reflect the local discharge policy when the study was conducted. Because length of hospitalization is influenced by many nonclinical factors (eg, health care system, surgeon preferences, and patient expectations), several authors advocate that LOS is not an ideal outcome to evaluate the effectiveness of ERPs. ${ }^{25,26}$ Alternative measures of in-hospital recovery have been described in the literature (eg, time to functional recovery ${ }^{25}$ and time to readiness for discharge $\mathrm{e}^{26}$ ) but none of the studies included in this review reported such measures.

None of the 3 studies evaluating overall complication rates reported differences between groups. ${ }^{19-21}$ Although this finding is reassuring for the safety of ERPs in lung resection, it does not corroborate studies in other surgical populations where overall complications were reduced in patients treated within an ERP. ${ }^{8}$ Because the studies

TABLE 3. Postoperative length of stay and readmission rates

\begin{tabular}{|c|c|c|c|c|c|c|c|c|}
\hline \multirow[b]{2}{*}{ Study } & \multicolumn{2}{|c|}{ Sample size } & \multicolumn{3}{|c|}{ Postoperative length of stay } & \multicolumn{3}{|c|}{ Readmission rates } \\
\hline & ERP & Control & ERP & Control & $P$ value & ERP & Control & $P$ value \\
\hline Salati, 2012 & 232 & 232 & $5.8 \pm 3.5$ & $8.6 \pm 4.7$ & $<.0001$ & $13(5.6 \%)^{*}$ & $12(5.2 \%)^{*}$ & 0.8 \\
\hline Numan, 2012 & 75 & 94 & $6.3(4-7)$ & $7.5(5-9)$ & .014 & $2(3 \%) \dagger$ & $9(10 \%) \dagger$ & 0.01 \\
\hline Muehling, 2008 & 30 & 28 & $11(8-33)$ & $11(7-34)$ & Not reported & Not reported & Not reported & Not reported \\
\hline Maruyama, 2006 & 113 & 105 & $13.3 \pm 0.9$ & $22.4 \pm 2.0$ & $<.0001$ & Not reported & Not reported & Not reported \\
\hline Zehr, 1998 & 241 & 185 & $6.1 \pm 3.4$ & $7.6 \pm 5.6$ & $<.002$ & Not reported & Not reported & Not reported \\
\hline Wright, 1997 & 130 & 147 & 7.5 & 10.6 & .03 & $3(2) \ddagger$ & $2(1) \ddagger$ & Not reported \\
\hline
\end{tabular}


TABLE 2. Continued

\begin{tabular}{|c|c|c|c|c|c|c|c|}
\hline \multirow{2}{*}{$\begin{array}{l}\text { Intraoperative } \\
\text { Prevention of } \\
\text { hypothermia }\end{array}$} & \multicolumn{7}{|c|}{ Postoperative } \\
\hline & $\begin{array}{l}\text { Standardized } \\
\text { chest tube } \\
\text { management }\end{array}$ & $\begin{array}{c}\text { Early removal } \\
\text { of epidural } \\
\text { catheter }\end{array}$ & $\begin{array}{c}\text { Early removal } \\
\text { of urinary catheter }\end{array}$ & $\begin{array}{l}\text { Postoperative fluid restriction/ } \\
\text { early discontinuation } \\
\text { of IV fluids }\end{array}$ & $\begin{array}{c}\text { Early removal } \\
\text { of oxygen support }\end{array}$ & $\begin{array}{l}\text { Early } \\
\text { feeding }\end{array}$ & $\begin{array}{c}\text { Early } \\
\text { mobilization }\end{array}$ \\
\hline \multirow{6}{*}{ レ } & & & & & & & \\
\hline & v & レ & & & & & $\nu$ \\
\hline & & & & $\boldsymbol{V}^{*}$ & & $\nu$ & $\nu$ \\
\hline & 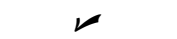 & $\nu$ & レ & $\nu$ & v & $\nu$ & $\nu$ \\
\hline & 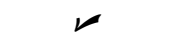 & & & & $\nu$ & $\nu$ & $\nu$ \\
\hline & 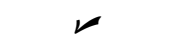 & $\nu$ & & & レ & & \\
\hline
\end{tabular}

included in this review were not specifically designed or powered to study complications, the lack of difference between groups may be explained by type II error. Complications were poorly defined and duration of follow-up was inconsistently reported, making it difficult to compare results across studies. In the RCT by Muehling and colleagues ${ }^{21}$ the rate of pulmonary complications was lower in the ERP group, which is encouraging for future research. In accordance with studies in other surgery populations, readmission rates were similar in patients treated with ERP or traditional care. ${ }^{8}$ This finding is particularly relevant given concerns that the early discharge seen with the ERP approach may increase hospital readmissions. ${ }^{7}$ Mortality rates were similar in patients treated with ERPs or traditional care, but studies were likely underpowered to detect differences in mortality. Two studies reported a significant cost reduction with the use of ERPs, ${ }^{17,22}$ but it is unclear what types of costs were included and how cost data were analyzed (eg, methods to estimate unit costs and overall costs). Only 1 study evaluated the influence of ERPs on PROs, suggesting a positive influence on postdischarge bodily pain and physical function. ${ }^{20}$

The ERP protocols identified in this review included a wide variety of elements. Unfortunately, there is currently no consensus or empirical evidence suggesting the optimal content of ERPs for lung resection. For this reason, it is difficult to make specific recommendations on which elements are essential to the program. Documenting the adherence to specific care elements provides the opportunity to better understand the relative contribution of individual elements; however, none of the studies identified in this review reported on adherence. Research in colorectal surgery suggests that increasing adherence ERP elements such as preoperative carbohydrate drinks and restriction of intravenous fluids is associated with improved postoperative outcomes, ${ }^{27}$ but there are no data specific to lung resection. Optimizing the content of ERPs, by including only elements that are essential, may reduce the complexity of protocols and make them less resource intensive.

Lung resection via VATS has been increasingly accepted as an alternative to open thoracotomy because evidence suggests that this approach is associated with fewer postoperative complications and earlier hospital discharge. ${ }^{28,29}$ Most of the studies in our systematic review did not include patients undergoing VATS or were conducted before this approach became routinely used in clinical practice ${ }^{17-19,21}$; therefore, the results cannot be generalized to the context of minimally invasive thoracic surgery. Research in others surgical specialties suggest that the combination of ERPs and minimally invasive surgery is an optimal treatment strategy to improve postoperative outcomes. ${ }^{30}$ Future research should investigate whether this also holds true for patients undergoing lung resection.

TABLE 4. Morbidity and mortality rates

\begin{tabular}{|c|c|c|c|c|c|c|c|c|}
\hline \multirow[b]{2}{*}{ Study } & \multicolumn{2}{|c|}{ Sample size } & \multicolumn{3}{|c|}{ Complication rates } & \multicolumn{3}{|c|}{ Mortality rates } \\
\hline & ERP & Control & ERP & Control & $P$ value & ERP & Control & $P$ value \\
\hline Salati, 2012 & 232 & 232 & $42(18)^{*}, \dagger$ & $38(16)^{*}, \dagger$ & .6 & Not reported & Not reported & Not reported \\
\hline Numan, 2012 & 75 & 94 & $13(17) \dagger$ & $13(14 \%) \dagger$ & .55 & 0 & 0 & \\
\hline Muehling, 2008 & 30 & 28 & $2(7 \%) \ddagger, \S 8(26) \ddagger$ & $10(36) \ddagger, \S 13(46) \ddagger$ & $\begin{array}{l}.009 \\
.172\end{array}$ & $1(3)$ & $1(4)$ & Not reported \\
\hline Maruyama, 2006 & 113 & 105 & Not reported & Not reported & Not reported & Not reported & Not reported & Not reported \\
\hline Zehr, 1998 & 241 & 185 & Not reported & Not reported & Not reported & $2(0.8) \ddagger$ & $1(0.5) \ddagger$ & Not reported \\
\hline Wright, 1997 & 130 & 147 & Not reported & Not reported & Not reported & $2(1.5) \|$ & $2(1.4) \|$ & Not reported \\
\hline
\end{tabular}

Values are presented as $\mathrm{n}(\%)$. ERP, Enhanced recovery pathway. *Thirty-day follow-up. †Only cardiopulmonary complications. $\ddagger$ Length of follow-up not reported. §Only pulmonary complications. ||Seven-day follow-up. 
This review was limited by the small number of studies identified and by their considerable risk of bias. We did not to conduct a formal analysis of statistical heterogeneity (eg, using $I^{2}$ statistics) due to the small number of studies available, ${ }^{31}$ but the substantial clinical and methodologic diversity across studies justify our decision not to conduct a meta-analysis. This review is subject to language bias because we targeted only articles in English or French. Also, publication bias favoring studies showing a positive effect of ERPs cannot not be excluded. For the purpose of this review we considered that patients were managed using an ERP if the authors documented the use of at least 4 care elements covering all phases of perioperative care (pre-, intra-, and postoperative). This definition, which was based on previous systematic reviews on ERPs, ${ }^{14}$ is somewhat arbitrary and subject to debate. Our decision to use the Cochrane risk of bias tool ${ }^{15}$ to evaluate risk of bias in both randomized and nonrandomized studies is also debatable. This decision was supported by the fact that the types of bias covered by Cochrane Tool should also be taken into account when interpreting the results of nonrandomized intervention studies (eg, risk of selection bias). ${ }^{15}$

\section{CONCLUSIONS}

We identified a small number of low-quality comparative studies evaluating the influence of ERPs in patients undergoing lung resection. Some nonrandomized studies yield encouraging results suggesting that ERPs may reduce primary LOS and hospitalization costs, but they should be interpreted in light of several methodologic limitations. This review highlights the need for well-designed trials to provide conclusive evidence about the role of ERPs in lung resection.

\section{Conflict of Interest Statement}

Authors have nothing to disclose with regard to commercial support.

\section{References}

1. Salati M, Refai M, Pompili C, Xiumè F, Sabbatini A, Brunelli A. Major morbidity after lung resection: a comparison between the European Society of Thoracic Surgeons Database system and the Thoracic Morbidity and Mortality system. J Thorac Dis. 2013;5:217-22.

2. Allen MS, Darling GE, Pechet TT, Mitchell JD, Herndon JE II, Landreneau RJ, et al. Morbidity and mortality of major pulmonary resections in patients with early-stage lung cancer: initial results of the randomized, prospective ACOSOG Z0030 trial. Ann Thorac Surg. 2006;81:1013-9.

3. Irshad K, Feldman LS, Chu VF, Dorval JF, Baslaim G, Morin JE. Causes of increased length of hospitalization on a general thoracic surgery service: a prospective observational study. Can J Surg. 2002;45:264-8.

4. Handy JJR, Asaph JW, Skokan L, Reed CE, Koh S, Brooks G, et al. What happens to patients undergoing lung cancer surgery?: outcomes and quality of life before and after surgery. Chest. 2002;122:21-30.

5. Lee L, Mata J, Ghitulescu GA, Boutros M, Charlebois P, Stein B, et al. Cost-effectiveness of enhanced recovery versus conventional perioperative management for colorectal surgery. Ann Surg. November 3, 2014 [Epub ahead of print].
6. Kehlet H, Wilmore DW. Evidence-based surgical care and the evolution of fast-track surgery. Ann Surg. 2008;248:189-98.

7. Paton F, Chambers D, Wilson P, Eastwood A, Craig D, Fox D, et al. Effectiveness and implementation of enhanced recovery after surgery programmes: a rapid evidence synthesis. BMJ Open. 2014;4:e005015.

8. Nicholson A, Lowe MC, Parker J, Lewis SR, Alderson P, Smith AF. Systematic review and meta-analysis of enhanced recovery programmes in surgical patients. Br J Surg. 2014;101:172-88.

9. Patton MD, Schaerf R. Thoracotomy, critical pathway, and clinical outcomes. Cancer Pract. 1995;3:286-94.

10. Bryant AS, Cerfolio RJ. The analysis of a prospective surgical database improves postoperative fast-tracking algorithms after pulmonary resection. J Thorac Cardiovasc Surg. 2009; 137:1173-9.

11. Cerfolio RJ, Pickens A, Bass C, Katholi C. Fast-tracking pulmonary resections. J Thorac Cardiovasc Surg. 2001;122:318-24.

12. McKenna RJ Jr, Mahtabifard A, Pickens A, Kusuanco D, Fuller CB. Fasttracking after video-assisted thoracoscopic surgery lobectomy, segmentectomy, and pneumonectomy. Ann Thorac Surg. 2007;84:1663-7.

13. Liberati A, Altman DG, Tetzlaff J, Mulrow C, Gotzsche PC, Ioannidis JPA, et al. The PRISMA statement for reporting systematic reviews and meta-analyses of studies that evaluate healthcare interventions: explanation and elaboration. BMJ. 2009;339:b2700.

14. Chambers D, Paton F, Wilson P, Eastwood A, Craig D, Fox D, et al. An overview and methodological assessment of systematic reviews and meta-analyses of enhanced recovery programmes in colorectal surgery. BMJ Open. 2014;4: e005014.

15. Higgins JPT, Green S. Cochrane handbook for systematic reviews of interventions version 5.1.0. www.cochrane-handbook.org. Accessed October 6, 2015.

16. Savovic J, Weeks L, Sterne J, Turner L, Altman D, Moher D, et al. Evaluation of the Cochrane Collaboration's tool for assessing the risk of bias in randomized trials: focus groups, online survey, proposed recommendations and their implementation. Syst Rev. 2014;3:37.

17. Zehr KJ, Dawson PB, Yang SC, Heitmiller RF. Standardized clinical care pathways for major thoracic cases reduce hospital costs. Ann Thorac Surg. 1998;66:914-9.

18. Wright CD, Wain JC, Grillo HC, Moncure AC, Macaluso SM, Mathisen DJ. Pulmonary lobectomy patient care pathway: a model to control cost and maintain quality. Ann Thorac Surg. 1997;64:299-302.

19. Salati M, Brunelli A, Xiume F, Refai M, Pompili C, Sabbatini A. Does fast-tracking increase the readmission rate after pulmonary resection? A case-matched study. Eur J Cardiothorac Surg. 2012;41:1083-7.

20. Numan RC, Klomp HM, Li W, Buitelaar DR, Burgers JA, Van Sandick JW, et al. A clinical audit in a multidisciplinary care path for thoracic surgery: an instrument for continuous quality improvement. Lung Cancer. 2012;78:270-5.

21. Muehling BM, Halter GL, Schelzig H, Meierhenrich R, Steffen P, SunderPlassmann L, et al. Reduction of postoperative pulmonary complications after lung surgery using a fast track clinical pathway. Eur J Cardiothorac Surg. 2008;34:174-80.

22. Maruyama R, Miyake T, Kojo M, Aoki Y, Suemitsu R, Okamoto T, et al. Establishment of a clinical pathway as an effective tool to reduce hospitalization and charges after video-assisted thoracoscopic pulmonary resection. Jpn J Thorac Cardiovasc Surg. 2006;54:387-90.

23. Lang P, Manickavasagar M, Burdett C, Treasure T, Fiorentino F. Suction on chest drains following lung resection: evidence and practice are not aligned. Eur J Cardiothorac Surg. April 12, 2015 [Epub ahead of print].

24. Cerfolio RJ, Bryant AS. Results of a prospective algorithm to remove chest tubes after pulmonary resection with high output. J Thorac Cardiovasc Surg. 2008; 135:269-73.

25. Maessen JM, Dejong CH, Kessels AG, von Meyenfeldt MF. Length of stay: an inappropriate readout of the success of enhanced recovery programs. World $J$ Surg. 2008;32:971-5.

26. Fiore J Jr, Faragher I, Bialocerkowski A, Browning L, Denehy L. Time to readiness for discharge' is a valid and reliable measure of short-term recovery after colorectal surgery. World J Surg. 2013;37:2927-34.

27. ERAS Compliance Group. The impact of enhanced recovery protocol compliance on elective colorectal cancer resection: results from an international registry. Ann Surg. 2015;261:1153-9.

28. Cao C, Manganas C, Ang SC, Yan TD. A meta-analysis of unmatched and matched patients comparing video-assisted thoracoscopic lobectomy and conventional open lobectomy. Ann Cardiothorac Surg. 2012;1:16-23. 
29. Boffa DJ, Dhamija A, Kosinski AS, Kim AW, Detterbeck FC, Mitchell JD, et al. Fewer complications result from a video-assisted approach to anatomic resection of clinical stage I lung cancer. J Thorac Cardiovasc Surg. 2014;148:637-43.

30. Zhuang CL, Huang DD, Chen FF, Zhou CJ, Zheng BS, Chen BC, et al. Laparoscopic versus open colorectal surgery within enhanced recovery after surgery programs: a systematic review and meta-analysis of randomized controlled trials. Surg Endosc. 2015;29:2091-100.
31. von Hippel PT. The heterogeneity statistic I(2) can be biased in small metaanalyses. BMC Med Res Methodol. 2015;15:35.

Key Words: lung cancer surgery, lobectomy, perioperative care, outcomes

\title{
EDITORIAL COMMENTARY
}

\section{"Moving right along" after lung resection, but the data suggest "not so fast"}

\author{
Lisa M. Brown, MD, MAS
}

\footnotetext{
From the Division of Cardiothoracic Surgery, Department of Surgery, University of California, Davis Medical Center, Sacramento, Calif.

Disclosures: Author has nothing to disclose with regard to commercial support.

Received for publication Oct 22, 2015; accepted for publication Oct 22, 2015; available ahead of print Dec 1, 2015.

Address for reprints: Lisa M. Brown, MD, MAS, 2221 Stockton Blvd, Room 2115, Sacramento, CA 95817

(E-mail: lmbrown@ucdavis.edu).

J Thorac Cardiovasc Surg 2016;151:715-6

$0022-5223 / \$ 36.00$

Copyright (c) 2016 by The American Association for Thoracic Surgery

http://dx.doi.org/10.1016/j.jtcvs.2015.10.081
}

During the last decade, there has been a boom in the interest of "fast track surgery," with numerous studies comparing standard perioperative care with enhanced recovery pathways (ERPs). The expectation is that ERPs will accelerate recovery, improve patient outcomes, and decrease hospital stay without increasing readmissions. In a meta-analysis of 38 trials of ERPs across all surgical subspecialties, ERPs reduced overall complication rates and hospital stay. ${ }^{1}$ Leading the way with fast track surgery is colorectal surgery, accounting for 18 of these 38 trials. A recent Cochrane review of 4 highly selected colorectal surgical randomized, controlled trials (RCTs) again showed a reduction in overall complications and stay for those treated with ERPs. ${ }^{2}$ Importantly, there was no difference in the readmission rate between the 2 groups. ${ }^{2}$ Despite these findings, the trials were deemed to be of low quality, and the reviewers cautioned against widespread implementation of ERPs. ${ }^{2}$ The literature surrounding ERPs in thoracic surgery is of even lower quality than that of colorectal surgery.

In this issue of the Journal, Fiore and colleagues have undertaken the task of completing an exhaustive literature search to identify the best evidence regarding ERPs for elective lung resection. Second, the authors should be applauded for comparing 6 disparate articles, an endeavor

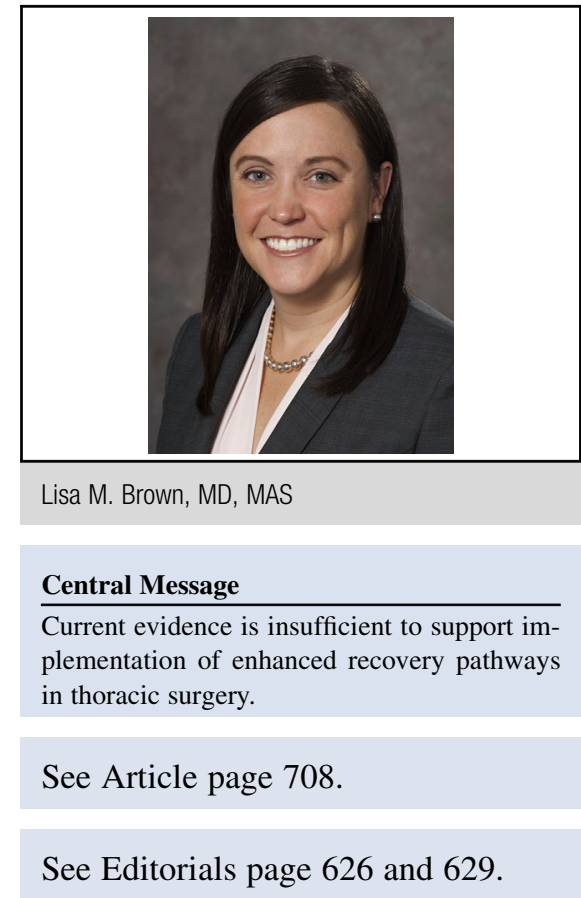

that is akin to comparing not just apples and oranges but apples to zucchini, because the methodologies for each study were vastly different. Finally, the authors' use of a descriptive approach is laudable, because the results of a true meta-analysis would be uninterpretable.

A common theme throughout this systematic review is that of biases affecting the results of ERP studies. There has been only a single RCT of ERPs in thoracic surgery, and it showed a decreased risk of pulmonary complications in the ERP arm (7\% vs 36\%) but no differences in overall morbidity or mortality. ${ }^{3}$ As Fiore and colleagues astutely 


\section{APPENDIX E1. SEARCH STRATEGIES}

\section{Medline via OvidSP (1946 to June 24, 2014)}

1. Thoracic Surgery/

2. Pulmonary Surgical Procedures/

3. exp Thoracoscopy/

4. Pneumonectomy/

5. (thoracoscop* or lobectom* or pneumonectom* or bronchoplast* or VATS).tw,kw.

6. ((resect* or surger* or surgical* or operati*) adj3 (lung or lungs or pulmonary or pneumo* or respirat*)).tw,kw.

7. exp lung/

8. Respiratory Tract Diseases/

9. exp Granuloma, Respiratory Tract/

10. exp lung diseases/

11. exp pleural diseases/

12. exp respiratory system abnormalities/

13. exp thoracic diseases/

14. respiratory tract neoplasms/

15. or $/ 7-14$

16. (resect* or surger* or surgical* or operati*).tw,kw.

17. surgery.fs.

18. 16 or 17

19. 15 and 18

20. 1 or 2 or 3 or 4 or 5 or 6 or 19

21. Critical Pathways/

22. ((clinical or critical or surger* or surgical* or patient or patients or care) adj3 (path or paths or pathway or pathways)).tw,kw.

23. ERAS.tw,kw.

24. ((enhanc* or rapid or earl*) adj3 recover*).tw,kw.

25. (fasttrack* or fast-track*).tw,kw.

26. or $/ 21-25$

27. 20 and 26

28. Animals/ not (Animals/ and Humans/)

29. 27 not 28

30. (exp child/ or exp infant/ or adolescent/) not ((exp child/ or exp infant/ or adolescent/) and exp adult/)

31. 29 not 30

\section{Medline via PubMed (1946 to 24/Jun/2014)}

1. thoracoscop*[Title/Abstract] or lobectom*[Title/ Abstract] or pneumonectom*[Title/Abstract] or bronchoplast*[Title/Abstract] or VATS[Title/Abstract]

2. thoracoscop*[Other Term] or lobectom*[Other Term] or pneumonectom*[Other Term] or bronchoplast* [Other Term] or VATS[Other Term]

3. (resect*[Title/Abstract] or surger*[Title/Abstract] or surgical*[Title/Abstract] or operati*[Title/Abstract]) AND (lung[Title/Abstract] or lungs[Title/Abstract] or pulmonary[Title/Abstract] or pneumol*[Title/ Abstract] or pneumonol*[Title/Abstract] or respirat* [Title/Abstract])
4. (resect*[Other Term] or surger*[Other Term] or surgical*[Other Term] or operati*[Other Term] $)$ AND (lung[Other Term] or lungs[Other Term] or pulmonary[Other Term] or pneumol*[Other Term] or pneumonol*[Other Term] or respirat*[Other Term])

5. (((\#1) OR \#2) OR \#3) OR \#4

6. (clinical[Title/Abstract] or critical[Title/Abstract] or surger*[Title/Abstract] or surgical*[Title/Abstract] or patient[Title/Abstract] or patients[Title/Abstract] or care[Title/Abstract]) AND (path[Title/Abstract] or paths[Title/Abstract] or pathway[Title/Abstract] or pathways[Title/Abstract])

7. (clinical[Other Term] or critical[Other Term] or surger*[Other Term] or surgical*[Other Term] or patient [Other Term] or patients[Other Term] or care[Other Term]) AND (path[Other Term] or paths[Other Term] or pathway[Other Term] or pathways[Other Term])

8. (ERAS[Title/Abstract]) OR ERAS[Other Term]

9. (enhanc*[Title/Abstract] or rapid[Title/Abstract] or earl*[Title/Abstract]) AND recover*[Title/Abstract]

10. (enhanc*[Other Term] or rapid[Other Term] or earl* [Other Term]) AND recover*[Other Term]

11. fasttrack*[Title/Abstract] or fast-track*[Title/Abstract]

12. fasttrack*[Other Term] or fast-track*[Other Term]

13. ((((( (\#6) OR \#7) OR \#8) OR \#9) OR \#10) OR \#11) OR $\# 12$

14. (\#5) AND \#13

15. publisher[sb] NOT pmcbook

16. (\#14) AND \#15

\section{Embase via OvidSP (via OvidSP 1947 to June 24, 2014)}

1. exp lung surgery/

2. thoracoscopy/

3. video assisted thoracoscopic surgery/

4. (thoracoscop* or lobectom* or pneumonectom* or bronchoplast* or VATS).tw,kw.

5. ((resect* or surger* or surgical* or operati*) adj3 (lung or lungs or pulmonary or pneumo* or respirat*)).tw,kw.

6. exp lung/

7. respiratory tract disease/

8. acute respiratory tract disease/

9. chronic aspecific respiratory tract disease/

10. chronic respiratory tract disease/

11. exp lung disease/

12. exp pleura disease/

13. exp thorax disease/

14. respiratory tract tumor/

15. respiratory tract cancer/

16. or/6-15

17. su.fs.

18. (resect* or surger* or surgical* or operati*).tw,kw.

19. 17 or 18 
20. 16 and 19

21. 1 or 2 or 3 or 4 or 5 or 20

22. clinical pathway/

23. ((clinical or critical or surger* or surgical* or patient or patients or care) adj3 (path or paths or pathway or pathways)).tw,kw.

24. ERAS.tw,kw.

25. ((enhanc* or rapid or earl*) adj3 recover*).tw,kw.

26. (fasttrack* or fast-track*).tw,kw.

27. 22 or 23 or 24 or 25 or 26

28. 21 and 27

29. (animal cell/ or animal experiment/ or animal model/ or animal tissue/) not ((animal cell/ or animal experiment/ or animal model/ or animal tissue/) and human/)

30. 28 not 29

31. (embryo/ or child/ or preschool child/ or school child/ or adolescent/ or (newborn/ and infant/)) not ((embryo/ or child/ or preschool child/ or school child/ or adolescent/ or (newborn/ and infant/)) and (adult/ or aged/))

32. 30 not 31

\section{Biosis Previews via OvidSP (1969 to 2014 Week 30)}

1. (thoracoscop* or lobectom* or pneumonectom* or bronchoplast* or VATS).tw.

2. ((resect* or surger* or surgical* or operati*) adj3 (lung or lungs or pulmonary or pneumo* or respirat*)).tw.

3. 1 or 2

4. ((clinical or critical or surger* or surgical* or patient or patients or care) adj3 (path or paths or pathway or pathways)).tw.

5. ERAS.tw.

6. ((enhanc* or rapid or earl*) adj3 recover*).tw.

7. (fasttrack* or fast-track*).tw.

8. or $/ 4-7$

9. 3 and 8

10. remove duplicates from 9

\section{CINAHL via Ebsco (1937 to June 24, 2014)}

1. MH "thoracic surgery"

2. (MH "Surgery, Lung+")

3. MH "thoracoscopy"

4. TI ((thoracoscop* or lobectom* or pneumonectom* or bronchoplast* or VATS)) OR AB ((thoracoscop* or lobectom* or pneumonectom* or bronchoplast* or VATS))

5. TI $\left(\left(\left(\right.\right.\right.$ resect* $^{*}$ or surger* or surgical* or operati*) N3 (lung or lungs or pulmonary or pneumo* or respirat*))) OR AB (((resect* or surger* or surgical* or operati*) $\mathrm{N} 3$ (lung or lungs or pulmonary or pneumo* or respirat*)))
6. (MH "Lung+")

7. (MH "Respiratory Tract Diseases")

8. (MH "Lung Diseases+")

9. (MH "Pleural Diseasest")

10. (MH "Respiratory System Abnormalities+")

11. (MH "Thoracic Diseases+")

12. (MH "Respiratory Tract Neoplasms")

13. S6 OR S7 OR S8 OR S9 OR S10 OR S 11 OR S12

14. MW surgery

15. TI ((resect* or surger* or surgical* or operati*)) OR AB ((resect* or surger* or surgical* or operati*))

16. S14 OR S15

17. S13 AND S16

18. S1 OR S2 OR S3 OR S4 OR S5 OR S17

19. (MH "Critical Path")

20. TI (((clinical or critical or surger* or surgical* or patient or patients or care) N3 (path or paths or pathway or pathways))) OR AB (((clinical or critical or surger* or surgical* or patient or patients or care) N3 (path or paths or pathway or pathways)))

21. TI ERAS OR AB ERAS

22. TI (((enhanc* or rapid or earl*) $\mathrm{N} 3$ recover* $))$ OR AB (((enhanc* or rapid or earl*) N3 recover*))

23. TI ((fasttrack* or fast-track*)) OR AB ((fasttrack* or fast-track*))

24. S19 OR S20 OR S21 OR S22 OR S23

25. S18 AND S24

Web of Science via ThomsonReuters (1996 to June 24, 2014)

1. $\mathrm{TS}=$ (thoracoscop* or lobectom* or pneumonectom* or bronchoplast* or VATS)

2. $\mathrm{TS}=\left(\left(\right.\right.$ resect* $^{*}$ or surger* or surgical* ${ }^{*}$ or operati* $)$ NEAR/3 (lung or lungs or pulmonary or pneumo* or respirat*))

3. \#2 OR \#1

4. $\mathrm{TS}=(($ clinical or critical or surger* or surgical* or patient or patients or care) NEAR/3 (path or paths or pathway or pathways))

5. $\mathrm{TS}=\mathrm{ERAS}$

6. $\mathrm{TS}=\left(\left(\right.\right.$ enhanc $^{*}$ or rapid or earl $\left.*\right) \mathrm{NEAR} / 3$ recover* $)$

7. $\mathrm{TS}=($ fasttrack $*$ or fast-track $*)$

8. \#7 OR \#6 OR \#5 OR \#4

9. \#8 AND \#3

\section{Scopus via Elsevier (1996 to June 24, 2014)}

1. TITLE-ABS-KEY(thoracoscop* or lobectom* or pneumonectom* or bronchoplast* or VATS)

2. TITLE-ABS-KEY((resect* or surger* or surgical* or operati*) W/3 (lung or lungs or pulmonary or pneumo* or respirat*))

3. \#1 OR \#2 
4. TITLE-ABS-KEY((clinical or critical or surger* or surgical* or patient or patients or care) W/3 (path or paths or pathway or pathways))

5. TITLE-ABS-KEY(eras)

6. TITLE-ABS-KEY((enhanc* OR rapid OR earl*) W/3 recover*)

7. TITLE-ABS-KEY(fasttrack* OR fast-track*)

8. \#4 OR \#5 OR \#6 or \#7

9. 8 AND \#3

\section{Cochrane Central Register Of Controlled Trials via The Cochrane Library (1995 to June 6, 2014)}

1. [mh "thoracic surgery"]

2. [mh "pulmonary surgical procedures"]

3. [mh thoracoscopy]

4. [mh pneumonectomy]

5. (thoracoscop* or lobectom* or pneumonectom* or bronchoplast* or VATS):ti,ab,kw

6. ((resect* or surger* or surgical* or operati*) near $/ 3$ (lung or lungs or pulmonary or pneumo* or respirat*)): ti,ab,kw

7. [mh lung]

8. [mh "respiratory tract diseases"]

9. [mh "granuloma, respiratory tract"]

10. [mh "lung diseases"]

11. [mh "pleural diseases"]

12. [mh "respiratory system abnormalities"]

13. [mh "thoracic diseases"]

14. [mh "respiratory tract neoplasms"]

15. $\{$ or \#7-\#14\}

16. (resect* or surger* or surgical* or operati*):ti,ab,kw

17. $[\mathrm{mh} / \mathrm{SU}]$

18. \#16 or \#17

19. \#15 and \#18

20. $\{$ or \#1-\#6, \#19\}

21. [mh "critical pathways"]

22. ((clinical or critical or surger* or surgical* or patient or patients or care) near/3 (path or paths or pathway or pathways)):ti,ab,kw

23. ERAS:ti,ab,kw

24. ((enhanc* or rapid or earl*) near/3 recover*):ti,ab,kw

25. (fasttrack* or fast-track*):ti,ab,kw

26. $\{$ or \#21-\#25\}

27. \#20 and \#26

\section{APPENDIX E2. EXCLUDED FULL-TEXT ARTICLES AND REASONS FOR EXCLUSION \\ Articles with no control group}

Bryant AS, Cerfolio RJ. The analysis of a prospective surgical database improves postoperative fast-tracking algorithms after pulmonary resection. J Thorac Cardiovasc Surg. 2009; 137:1173-9.
Cerfolio RJ, Pickens A, Bass C, Katholi C. Fast-tracking pulmonary resections. J Thorac Cardiovasc Surg. 2001; 122:318-24.

Dango S, Offner K, Kirschbaum A, Loop T, Passlick B. Epidural analgesia in thoracic surgery-optimising postoperative rehabilitation. Zentralbl Chir. 2008; 133: 491-7.

Das-Neves-Pereira JC, Bagan P, Coimbra-Israel AP, et al. Fast-track rehabilitation for lung cancer lobectomy: a five-year experience. Eur J Cardiothorac Surg. 2009; 36:383-91; discussion 91-2.

Dumans-Nizard V, Guezennec J, Parquin F, et al. Feasibility and results of a fast-track protocol in thoracic surgery. Minerva Anestesiol. 2015 Mar 13. Epub ahead of print.

Gregor JI, Schwenk W, Mall J, et al. "Fast-track" rehabilitation in thoracic surgery. First experiences with a multimodal, interdisciplinary, and proven perioperative treatment course. Chirurg. 2008; 79:657-64.

McKenna RJ Jr, Mahtabifard A, Pickens A, Kusuanco D, Fuller CB. Fast-tracking after video-assisted thoracoscopic surgery lobectomy, segmentectomy, and pneumonectomy. Ann Thorac Surg. 2007; 84:1663-7.

Okita A, Yamashita M, Abe K, et al. Variance analysis of a clinical pathway of video-assisted single lobectomy for lung cancer. Surgery. 2009; 39:104-9.

Padilla Alarcon J, Penalver Cuesta JC. Experience with lung resection in a fast-track surgery program. Arch Bronconeumol. 2013; 49:89-93.

Shoji F, Yano T, Haro A, et al. Assessing a clinical pathway to improve the quality of care in pulmonary resections. Surgery. 2011; 41:787-90.

Smith RS, Rescorla FJ, Hoffman JP, Preventza O. Fast track video-assisted thoracic surgery: Discussion. Am Surgeon. 2002; 68:311.

Tovar EA. Minimally invasive approach for pneumonectomy culminating in an outpatient procedure. Chest. 1998; 114:1454-8.

Tovar EA. One-day admission for major lung resections in septuagenarians and octogenarians: a comparative study with a younger cohort. Eur J Cardiothorac Surg. 2001; 20:449-53; discussion 53-4.

Tovar EA, Roethe RA, Weissig MD, Lloyd RE, Patel GR. One-day admission for lung lobectomy: an incidental result of a clinical pathway. Ann Thorac Surg. 1998; 65:803-6.

Ueda K, Kaneda Y, Sakano H, Tanaka T, Li TS, Hamano $\mathrm{K}$. Obstacles for shortening hospitalization after videoassisted pulmonary resection for lung cancer. Ann Thorac Surg. 2003; 76:1816-20.

Ueda K, Sudoh M, Jinbo M, Li TS, Suga K, Hamano K. Physiological rehabilitation after video-assisted lung lobectomy for cancer: a prospective study of measuring daily exercise and oxygenation capacity. Eur J Cardiothorac Surg. 2006; 30:533-7. 


\section{Conference abstract}

Abdelaziz M, Bradley A, Agostini P, et al. A multidisciplinary complex perioperative intervention to reduce complications and enhance recovery after lung resection surgery. Lung Cancer. 2011; 71:S26.

Barbetakis N, Vassiliadis M, Paliouras D, et al. Fast-track rehabilitation following video-assisted thoracic surgery for solitary or multiple pulmonary nodules. $J$ Cardiothorac Vascular Anesth. 2009; 1(Suppl):S40.

Carbon R, Roman C, Bertram R, Peter HH, Stefanie K. Fast track surgery of recurrent pneumothraces in patients with cystic fibrosis - Superiority of minimally invasive tissue management. Inflamm Res. 2007; 56:S272.

Coad J, Sharkey AJ, Owen-Smith R, et al. Standardising the management of patients following lung resection: Does it improve outcome? J Thorac Oncol. 2013; 8(Suppl): S391.

Creedon L, Hagan M, Martin-Ucar AE, Internullo E, Socci L, Malik M. Enhanced recovery after pulmonary surgery protocols help reduce use of resources without compromising outcomes. Interact Cardiovasc Thoracic Surg. 2012; 15(Suppl):S18.

Evman S, Ermerak NO, Issaka A, et al. Is there a correlation between postoperative complications and timing of oral intake after thoracotomy? Interact Cardiovasc Thorac Surg. 2012; 15:S47-S8.

Kistemaker B, Veenstra W, Bakker MSN. A multidiscplinary care-pathway for lung surgery... 7th EONS Spring Convention in partnership with V\&VN, 15-16 April 2010, The Hague, The Netherlands. Eur J Oncol Nurs. 2010; 14:S37-8.

Nam B, Weigel T. An adaptable acuity care unit (AACU) model facilitates fasttracking of video-assisted thoracic surgery (VATS) lobectomy patients. Ann Surg Oncol. 2012; 19(Suppl):S133-S4.

Numan RC, Burgers JA, Vd Noort V, Klomp HM, Wouters MW. Functional outcome after pulmonary metastasectomy: video-assisted thoracoscopic surgery versus thoracotomy. Eur J Cancer. 2013; 49(Suppl): S803-S4.

Schermer S, Schatz C, Tabor C, Khandhar S, Fortes D, Krenzischek D. The valuable role of perianesthesia nursing in fast tracking minimally invasive thoracic surgery patients. J PeriAnesthes Nurs. 2013; 28:e16-e.

Terauchi K, Shimada J. Preoperative oral rehydration in patients undergoing thoracoscopic surgery for lung cancers. J Thorac Oncol. 2013; 8(Suppl):S262.

Vayvada M, Coskun T, Tasci E, Olgac G, Kutlu CA. How early can we discharge our patients safely following a major lung resection? Interact Cardiovasc Thorac Surg. 2012; 15:S53.

Wotton R, West D, Collins F, Casali G, Batchelor T. Enhanced recovery after lobectomy: Vats approach reduces hospital stay. Innovat Technol Technique Cardiothorac Vasc Surg. 2012; 7 (2):157-8.

Zhang Y, Li YB, Liu BD, et al. [A comparative study of complete video-assisted thoracoscopic lobectomy and video-assisted mini-thoracotomy in treatment of lung cancer]. Chung Hua I Hsueh Tsa Chih. 2013; 93:2972-5.

\section{Review article/Editorial}

Bryant AS, Cerfolio RJ. The influence of preoperative risk stratification on fast-tracking patients after pulmonary resection. Thorac Surg Clin. 2008; 18:113-8.

Cerfolio RJ, Bryant AS. Does minimally invasive thoracic surgery warrant fast tracking of thoracic surgical patients? Thorac Surg Clin. 2008; 18:301-4.

Elsayed H, Poullis M. Should paravertebral analgesia be used to fast track patients after thoracic surgery? Eur $J$ Cardiothorac Surg. 2009; 35:188; author reply -9.

Freixinet JL, Rodriguez PM. Fast track in thoracic surgery. Asian Cardiovasc Thorac Ann. 2008; 16:187-8.

Jones NL, Edmonds L, Ghosh S, Klein AA. A review of enhanced recovery for thoracic anaesthesia and surgery. Anaesthesia. 2013; 68:179-89.

Muhling B, Orend KH, Sunder-Plassmann L. [Fast track in thoracic surgery]. Chirurg. 2009; 80:706-10.

Wilmore DW. Therapy which enhances surgical recovery: the potential for multimodality, fast-track surgery in the 21st century. Nippon Geka Gakkai Zasshi. 2000; 101:281-3.

\section{ERP did not cover all phases of perioperative care}

Mo J, Oh H, Ahn Y, Seo W. Implementation of a clinical pathway in primary spontaneous pneumothorax patients treated by wedge resection surgery. Clin Nurse Spec. 2010; 24:295-303.

Schwarzbach M, Rossner E, Schattenberg T, Post S, Hohenberger P, Ronellenfitsch U. Effects of a clinical pathway of pulmonary lobectomy and bilobectomy on quality and cost of care. Langenbecks Arch Surg. 2010; 395:1139-46.

Schwarzbach MH, Ronellenfitsch U, Wang Q, et al. Effects of a clinical pathway for video-assisted thoracoscopic surgery (VATS) on quality and cost of care. Langenbecks Arch Surg. 2010; 395:333-40.

Sokouti M, Aghdam BA, Golzari SEJ, Moghadaszadeh M. A comparative study of postoperative pulmonary complications using fast track regimen and conservative analgesic treatment: A randomized clinical trial. Tanaffos. 2011; 10:12-9.

Matzi V, Lindenmann J, Muench A, et al. The impact of preoperative micronutrient supplementation in lung surgery. A prospective randomized trial of oral supplementation of combined alpha-ketoglutaric acid and 5-hydroxymethylfurfural. Eur J Cardiothorac Surg. 2007; 32:776-82. 


\section{Did not involve lung resection}

Aasebo U, Strom HH, Postmyr M. The Lean method as a clinical pathway facilitator in patients with lung cancer. Clin Respir J. 2012; 6:169-74.

Hatada A, Bessho T, Arimoto J, et al. Clinical pathway for the treatment of primary spontaneous pneumothorax in wakayama national hospital. J Wakayama Med Soc. 2007; 58:166-8.

Malik M, Black EA. Fast-track video-assisted bullectomy and pleurectomy for pneumothorax: initial experience and description of technique. Eur J Cardiothorac Surg. 2009; 36:906-9.

\section{Article in another language}

Iijima K, Nakagawa K, Okumura S, Sato Y, Tsuchiya S. A clinical pathway for pulmonary resections with conventional thoracotomies in patients with neoplastic diseases [Article in Japanese]. Jpn J Lung Cancer. 2003; 43:113-20.

Lee SC, Tseng HY, Wang KY, Lee LC. Effect of a clinical pathway on selected clinical outcomes of pulmonary lobectomy. Chung Hua I Hsueh Tsa Chih (Taipei). 2002; 65:7-12.

Zhao G, Huang Y, Chen X, et al. Research on fast track surgery application in lung cancer surgery [Article in Chinese]. Zhongguo Fei Ai Za Zhi. 2010; 13:102-6. 
APPENDIX E3. Sample characteristics

\begin{tabular}{|c|c|c|c|c|c|c|c|c|c|c|c|c|}
\hline \multirow[b]{2}{*}{ Study } & \multicolumn{2}{|c|}{ Sample size } & \multicolumn{2}{|c|}{ Age } & \multicolumn{2}{|c|}{ Male gender } & \multicolumn{2}{|c|}{ ASA score } & \multicolumn{2}{|c|}{ BMI } & \multicolumn{2}{|c|}{ FEV1 ( $\%$ predicted $)$} \\
\hline & ERP & Control & ERP & Control & ERP & Control & ERP & Control & ERP & Control & ERP & Control \\
\hline $\begin{array}{l}\text { Salati, } \\
2012\end{array}$ & 232 & 232 & $68.2 \pm 9.4$ & $67.7 \pm 10.8$ & $\begin{array}{c}\text { Not } \\
\text { reported }\end{array}$ & $\begin{array}{c}\text { Not } \\
\text { reported }\end{array}$ & $1.9 \pm 0.6$ & $2 \pm 0.6$ & $26.3 \pm 4.8$ & $26.5 \pm 3.8$ & $84.6 \pm 18.5$ & $85.7 \pm 19$ \\
\hline $\begin{array}{c}\text { Numan, } \\
2012\end{array}$ & 75 & 94 & $60(21-78)$ & $58(24-83)$ & $43(57)$ & $55(58)$ & Not reported & Not reported & $25(22-27)$ & $26(23-28)$ & $95(82-104)$ & $92(77-101)$ \\
\hline $\begin{array}{l}\text { Muehling, } \\
2008\end{array}$ & 30 & 28 & $67(45-81)$ & $64(24-83)$ & $20(66)$ & $23(82)$ & $\begin{array}{c}\text { ASA II } \\
4(13) \\
\text { ASA III } \\
24(80) \\
\text { ASA IV } \\
2(6)\end{array}$ & $\begin{array}{c}\text { ASA II } \\
5(18) \\
\text { ASA III } \\
23(82) \\
\text { ASA IV } \\
2(7)\end{array}$ & $\begin{array}{l}\text { Not } \\
\text { reported }\end{array}$ & $\begin{array}{l}\text { Not } \\
\text { reported }\end{array}$ & $\begin{array}{l}\text { Not } \\
\text { reported }\end{array}$ & $\begin{array}{c}\text { Not } \\
\text { reported }\end{array}$ \\
\hline $\begin{array}{l}\text { Maruyama, } \\
2006\end{array}$ & 113 & 105 & $63(17-84)$ & $64(15-83)$ & $66(58)$ & $53(55)$ & Not reported & Not reported & $\begin{array}{l}\text { Not } \\
\text { reported }\end{array}$ & $\begin{array}{c}\text { Not } \\
\text { reported }\end{array}$ & $\begin{array}{c}\text { Not } \\
\text { reported }\end{array}$ & $\begin{array}{c}\text { Not } \\
\text { reported }\end{array}$ \\
\hline Zehr, 1998 & 241 & 185 & $63.7 \pm 11.5$ & $61.8 \pm 11.7$ & $\begin{array}{c}\text { Not } \\
\text { reported }\end{array}$ & $\begin{array}{c}\text { Not } \\
\text { reported }\end{array}$ & Not reported & Not reported & $\begin{array}{l}\text { Not } \\
\text { reported }\end{array}$ & $\begin{array}{l}\text { Not } \\
\text { reported }\end{array}$ & $\begin{array}{c}\text { Not } \\
\text { reported }\end{array}$ & $\begin{array}{l}\text { Not } \\
\text { reported }\end{array}$ \\
\hline $\begin{array}{c}\text { Wright, } \\
1997\end{array}$ & 130 & 147 & 60 & 60 & $71(55)$ & $81(55)$ & Not reported & Not reported & $\begin{array}{c}\text { Not } \\
\text { reported }\end{array}$ & $\begin{array}{c}\text { Not } \\
\text { reported }\end{array}$ & $\begin{array}{c}\text { Not } \\
\text { reported }\end{array}$ & $\begin{array}{c}\text { Not } \\
\text { reported }\end{array}$ \\
\hline
\end{tabular}

Values are presented as mean \pm standard deviation, mean (interquartile range), mean, or $\mathrm{n}(\%) . A S A$, American Society of Anesthesiologists; BMI, body mass index; $F E V I$, forced expiratory volume in 1 second; $E R P$, enhanced recovery pathway.

\begin{tabular}{|c|c|c|c|c|c|c|}
\hline \multirow[b]{2}{*}{ Study } & \multicolumn{2}{|c|}{ Preoperative diagnosis } & \multicolumn{2}{|c|}{ Surgical approach } & \multicolumn{2}{|c|}{ Extent of resection } \\
\hline & ERP & Control & ERP & Control & ERP & Control \\
\hline $\begin{array}{l}\text { Salati, } 2012 \\
\text { Numan, } 2012\end{array}$ & $\begin{array}{l}\text { Not reported } \\
\text { Primary cancer } 38(51) \\
\text { Metastasis } 32 \text { (43) } \\
\text { Other } 5 \text { (7) }\end{array}$ & $\begin{array}{l}\text { Not reported } \\
\text { Primary cancer } 42(45) \\
\text { Metastasis } 37(39) \\
\text { Other } 15(16)\end{array}$ & $\begin{array}{l}\text { Not reported } \\
\text { Open } 50(67) \\
\text { VATS } 25(33)\end{array}$ & $\begin{array}{l}\text { Not reported } \\
\text { Open } 79(84) \\
\text { VATS } 15(16)^{*}\end{array}$ & $\begin{array}{l}\text { Lobectomy } 232(100) \\
\text { Lobectomy/ } \\
\quad \text { segmentectomy } \\
\quad 34(45) \\
\text { Wedge } 31(41) \\
\text { Other } 10(13)\end{array}$ & $\begin{array}{l}\text { Lobectomy } 100 \% \\
\text { Lobectomy/ } \\
\quad \text { segmentectomy } \\
\quad 42(45) \\
\text { Wedge } 38(40) \\
\text { Unknown } 14(15)\end{array}$ \\
\hline $\begin{array}{l}\text { Muehling, } \\
2008\end{array}$ & $\begin{array}{l}\text { Primary cancer } 25(83) \\
\text { Metastases } 3(10) \\
\text { Carcinoid } 1(3) \\
\text { PEComa } 1(3)\end{array}$ & $\begin{array}{l}\text { Primary cancer } 19 \text { (68) } \\
\text { Metastases } 4 \text { (14) } \\
\text { Carcinoid } 1 \text { (4) } \\
\text { Aspergilloma } 1 \text { (4) } \\
\text { Pneumonia } 1 \text { (4) } \\
\text { Bulla } 1 \text { (4) } \\
\text { Mesothelioma 1 (4) }\end{array}$ & Open 30 (100) & Open 28 (100) & $\begin{array}{l}\text { Lobectomy } 18(60) \\
\text { Wedge } 6(20) \\
\text { Bilibectomy } 2(7) \\
\text { Pneumotomy } 3(10) \\
\text { Sleeve resection } 1 \text { (3) }\end{array}$ & $\begin{array}{l}\text { Lobectomy } 19 \text { (68) } \\
\text { Wedge } 5 \text { (18) } \\
\text { Bilibectomy } 1 \text { (4) } \\
\text { Pneumotomy } 1 \text { (4) } \\
\text { Sleeve resection } 2 \text { (7) }\end{array}$ \\
\hline $\begin{array}{c}\text { Maruyama, } \\
2006\end{array}$ & $\begin{array}{l}\text { Primary cancer } 79(62) \\
\text { Metastases } 22(19) \\
\text { Benign tumor } 6(5) \\
\text { Inflammatory lesion } \\
\quad 2(2) \\
\text { Organized pneumonia } \\
\quad 2(2) \\
\text { Others } 2(2)\end{array}$ & $\begin{array}{l}\text { Primary cancer } 67(63) \\
\text { Metastases } 19(18) \\
\text { Benign tumor } 6(6) \\
\text { Inflammatory lesion } \\
\quad 4(4) \\
\text { Organized pneumonia } \\
\quad 1(1) \\
\text { Others } 8(8)\end{array}$ & VATS $113(100)$ & VATS $105(100)$ & $\begin{array}{l}\text { Lobectomy } 64 \text { (56) } \\
\text { Wedge/ } \\
\text { segmentectomy } \\
46(41) \\
\text { Bilibectomy/ } \\
\text { pneumectomy } 3 \text { (3) }\end{array}$ & $\begin{array}{l}\text { Lobectomy } 58 \text { (55) } \\
\text { Wedge/ } \\
\text { segmentectomy } 46 \text { (44) } \\
\text { Bilibectomy/ } \\
\text { pneumectomy } 1 \text { (1) }\end{array}$ \\
\hline Zehr, 1998 & Not reported & Not reported & Not reported & Not reported & $\begin{array}{l}\text { Segmentectomy } \\
83(34) \\
\text { Lobectomy } 154(64) \\
\text { Pneumonectomy } 4 \text { (1) }\end{array}$ & $\begin{array}{l}\text { Segmentectomy } 142 \text { (77) } \\
\text { Lobectomy } 36 \text { (19) } \\
\text { Pneumonectomy } 7 \text { (4) }\end{array}$ \\
\hline Wright, 1997 & Not reported & Not reported & Not reported & Not reported & Lobectomy 130 (100) & Lobectomy 147 (100) \\
\hline
\end{tabular}

Values are presented as $\mathrm{n}(\%)$. ERP, Enhanced recovery pathway; VATS, video-assisted thoracic surgery. ${ }^{*} P<.05$. 